\title{
Geriatrics and gastroentero
Time to wake up to the ageing problem
}

or

The ageing gastrointestinal tract, the ageing physician and Canadian prejudice in perspective

\author{
ABR THOMSON, MD, PHD, FRCPC
}

C ANADA IS A NATION OF IMMIGRANTS (NEWCOMERS) and each of these special new groups brings its own perspective on ageing. It is the decline in Canadian fertility that is the major cause of population ageing. Research is destroying the myths that older people are isolated from and abandoned by their families.

This of course does not imply that family life is completely positive - families are "emotionally intense environments, conflict is as characteristic of family life as cooperation is."

Yes, we are growing old. In 1980 there were approximately 3.2 million Canadians aged 60 years or more, and if projections are correct, this figure will increase to 4.5 million by the turn of the century. Half the members of the Canadian Association of Gastroenterology may find themselves in this group. As individuals we may wish to imagine living out our older years as

creative, alert, healthy individuals, living as we choose, perhaps in family settings, perhaps in our own homes or in cooperative apartment units, or perhaps we look forward to living alone, on our own individual time table.

As pointed out by RA Schlesinger (1), "in actuality, many of us will be living in institutions, in senior citizen housing units, or with our children in joint households."

The 1960s made us aware of the problems of child abuse. The 1970s focused attention on wife battering. And in the 1980s we are becoming aware of still another form of family violence, one that the English have labelled 'granny bashing.' This abuse may be physical, psychological or economic. It

Comrespondence and reprints: Dr ABR Thomson, 519 Newton Research Building, University of Alberta, Edmonton, Alberta T6G $2 \mathrm{C2}$ strikes individuals who are powerless to defend themselves. Prevention is crucial, and there are a number of methods of deterrence:

reversing our society's approval and promotion of violence in the community and at home; using all possible means to reduce stresses within families because these are the forerunners of violence and abuse; facilitating meaningful relationships between families and their neighbors and communities to counteract the isolated existence of so many; changing the balance of power, decision-making and sharing of household tasks to alleviate the gross inequalities with discrimination towards elderly and women; interrupting the historical patterns of violence in generations of families.

I leave the last word to Schlesinger (1):

We fight for quality of life. Why are we silent when our mothers and grandmothers struggle alone and in silence in their battle for survival, for growing old in an atmosphere of dignity and understanding? We must provide the strength for those who no longer have such strength. We must hear the silent cries, and our voices must help them speak. We too will grow old, and we too want to live in a world of mutual respect, love and care, not increased elderly abuse, not in a world of 'granny-bashing.'

Within most of our memories the elders - grandparents, great aunts and uncles - were among the most revered relatives and members of society. We must provide a means by which our elderly can look forward to an old age surrounded by the love and care of their children and grandchildren, the nurture of the community and the respect which is their due.

In Geriatric Gastroenterology (2), Sodeman et al have wished "to simplify the introduction to [the 'encyclopedias' or the papers] the topic of digestive tract problems in the elderly, written with the needs of the primary care physician in mind." 
And with whát success? The discussion of SIDES (symptomatic, idiopathic, diffuse esophageal spasm) is well considered, but the distinction from angina pectoris may be difficult since the pain of SIDES has occasionally been associated with exercise and with drugs that relax smooth muscle - there is no differentiation between esophageal and coronary artery musculature. Unfortunately, the references on the esophagus are themselves 'old' with none more recent than 1986. We are implored that "old stomachs should evoke respect from physicians; these organs must have served their owners well for neither would be old!" It is important for us to appreciate that "vague manifestations, intractability, and reduced rate of recurrence seem to be the hallmarks of the ulcer syndrome in older patients," that pain may often be absent and that the clinical presentation may be dominated by systemic symptoms. Some may find it surprising that at least one-quarter of cases of gluten-sensitive enteropathy will first appear after age 70. Chronic ischemia is responsible for the two well recognized clinical syndromes of intestinal angina (usually presenting clinically as postprandial crampy abdominal discomfort that comes on in the first half hour after a meal and persists for several hours) and malabsorption. While constipation may be common in the elderly, "communication with the elderly concerning bowel habits takes patience, largely in the definition of terms," with the first focus being on identification of the patient's own customary pattern of bowel habits. The section on management of constipation with the use of laxatives and cathartics is particularly well prepared.

Unfortunately, however, there remains the perspective that geriatric gastroenterology is simply gastroenterology in the elderly, ie, there are no unique conditions seen in the elderly but simply an accumulation of conditions often seen in younger patients (except perhaps for sigmoid and cecal volvulus which are much more common in the elderly, but do still appear in young individuals). Unfortunately there is no discussion of AIDS in the elderly; since this book is aimed at providing an overview and introduction for the primary care physician, consideration of such topics would be appropriate - age is no barrier in the bedrooms of the nation. An important area for reflection is the consideration of drugs and the liver, in which we are reminded that certain drugs behave sufficiently distinctly in the elderly patient to merit individual comment. Isoniazide is more likely to produce hepatotoxicity in an older individual; halothane hepatitis may also occur more frequently in the elderly; and benoxaprofen causes death in association with jaundice and renal failure predominantly in the elderly. While hepatitis A is less common in the elderly, one occasionally sees hepatitis $\mathrm{A}$ in a grandparent who contracted it from a child in a school setting. The most common cause of viral hepatitis in the elderly is non-A,non-B hepatitis, most often acquired from blood transfusions. Viral hepatitis is not necessarily more fatal in older patients. Remember that cardiac disease is an important cause of liver enzyme abnormalities with emphasis on congestive hepatopathy (moderate alkaline phosphatase elevation, mild hyperbilirubinemia and minimal elevation of transaminases), as is ischemic hepatitis with centrilobular necrosis and a clinical presentation similar to mild viral hepatitis in a patient with heart disease; the patient may have a myocardial infarction or arrhythmia and then have developed a transient rapid rise in transaminases without concomitant bilirubin elevation. Another relatively common cause of abnormal liver tests from an extrahepatic source is bacterial infection, the most notorious of which is lobar pneumonia with mild hyperbilirubinemia and mild elevation of alkaline phosphatase. Rarely, reactions from paraneoplastic syndromes may occur in conjunction with Hodgkin's disease and renal cell carcinoma. Some elderly patients will present with variceal hemorrhage without alcohol abuse or prior liver disease - a recent problem population presenting in a nonhepatic manner. The elderly patient has a particular risk of developing acalculous cholecystitis in association with other significant illnesses such as sepsis, trauma, metabolic disorders or postoperative state. Indeed, any right upper quadrant syndrome or even unexplained elevations of liver enzyme tests of appropriate magnitude should raise the spectre of acalculous cholecystitis.

Thus, this short book has provided a number of timely reminders of gastrointestinal disorders which will certainly be seen in the octogenarian. Because the book is aimed at the primary care physician (which includes many of us), the authors could be excused for not including a section on the theories of ageing. Of greatest concern to us all is the question "What can we do about it?" - ie, are any of these processes potentially reversible with interventional therapy? Just how useful is diet modification to prevent colon cancer? Should elderly patients taking nonsteroidal anti-inflammatory drugs always be placed on prophylactic therapy with, for example, misoprostol? These are difficult issues, but realistic ones which we all face from time to time for which guidance would be appreciated from the experts.

Finally, I must comment on the cost of this 'wee' book. The price is just under $\$ 60.00$ for 211 pages - I seriously question the value of more than 'two bits' per page. Because authors of medical books usually receive a less than $12 \%$ royalty fee, none of the authors of this work would be able to buy a Big Mac from my purchase. I plead for cheaper books, more recent references and the consideration of important clinical concerns.

But let us not stop with the gastrointestinal tract. As gastroenterologists we may view the aspect of ageing from the simple perspective of the lumen and appendices of a tubular structure! Really, the major criticism of this recent (albeit understandable) text is the lack of attention to social perspectives. It is this attention to an important aspect of the human condition which directs my arousal toward a 'must read' by Marshall (3). As correctly stated in the preface,

this book is aimed at a diverse audience of social and health science students, social service and health care personnel, policy makers and research-oriented scholars, advocates of and activists for and among the aged. The chapters commissioned for the book accordingly represent diverse interests that are united by a common concern with the social aspects of aging. 
There is a central debate in gerontology, the 'rectangularization' thesis, which suggests that the shape of the morbidity curve will rectangularize towards a natural limit, assuming a shape very close to a similarly developing rectangularization of mortality. As the proportion of the aged population increases, more creative and ambitious efforts will be needed to respond to concerns for maintenance and improvement of quality of life for the aged. We must separate our attitude towards our own ageing from our attitude towards the aged.

In the world context, Canada is an 'old' society, with about one in 10 Canadians aged 65 or more. Ageing is not simply of social interest to the old; people of all ages are affected by the ageing of the population. If we target social services on the basis of age rather than need, we risk reinforcing negatively consequential stereotypes of the aged. There are 'micro' and 'macro' sides to ageing, personal and social sides, and inside andoutside views. 'Old age' in Canadian society is "principally defined as a consequence of our developing (or adopting) a social institution called retirement." It is my suggestion that forced retirement is one of the major factors leading to our current prejudice regarding the attributes of ageing, that we as physicians must act as advocates of the abilities rather than the so-called disabilities of our genealogically older patients, and that we must recognize that some of our collegial group will remain quite competent to practise medicine into their 70s. Your perspective may be heavily influenced by your own proximity to that age of planned senescence!

Gerontology is not a scientific discipline, but rather a focal point that draws the attention of many disciplines. Medicine and gastroenterology are among these focal points, but only one of many others such as economics, demography, political science, sociology, anthropology, epidemiology, psychology and biology. Marshall suggests that "the social domain calls for a distinctively Canadian research contribution"; perhaps an even more important area for distinctive Canadian contribution rests in the area of the dismantling of the artificial and intolerably prejudiced Bismarckian concept of compulsory retirement. Why should the perspective on the revitalization of attitudes towards ageing be any different in Canada? Marshall argues that

in general, theory about aging in Canada is more structural, collectivist and historically grounded than the predominantly attitudinal, individualistic and consensually oriented theorizing south of the border ... We have drawn heavily on Marxist and Weberian strains in social economic theory, and on the European phenomenologists and American symbolic interactionists for our social psychology.

Not all old people are passive recipients of the behaviour of others; some will negotiate their status. But it will be too late if we as individuals wait to minimize the weaknesses of old age. We must instead begin now to employ strategies designed to maintain and extend not only the authority of all elderly, but of old physicians as well. The basis must not just be argument-based unfair play. Our society is built on a capitalist economy and democratic policy, the inherent contradiction of our current social democratic welfare state must be exploited to the benefit of both the elderly and the 'senior' physician.

With the 'humanization' of medicine - better working conditions for doctors in training, better opportunities for continued medical education and study leave, better acceptance of group practice with allowable time for family life and personal development, and better acceptance of physicians as persons rather than as superhumans - we may soon be better yet, sooner still ready to find the appropriate role of the older physician. The problem lies not in the fine tuning of the solution, but rather in the recognition that there is a problem.

While contact with the elderly within a family situation may be burdensome, literature on caregiving suggests that families do not, contrary to popular belief, abandon their elders. Let us therefore also not abandon our senior physicians. As individuals in a profession, we must adopt a flexibility which will permit fluctuations in dependency and power. Just as grandparenting can be a potentially significant and meaningful force in the lives of older adults, so too there is a place for senior physicians in the teaching of students, their opinions based on experience, and their continued desire to contribute. This attitude is based on respect for the worth of such individuals, not on a shortsighted view of man as an economic entity and of the senior physician being nothing more than a 'stop' (arrête) sign to the appointment of the young.

In our early years, age is a significant factor in determining one's friends and peers, and in late adulthood we see a return to the consideration of age as a salient characteristic for defining one's peer group. But the collegial spirit, responsibility and dedication which cement respectful interaction between physicians must surely be a bond which will allow us to define more clearly a participative role for all - we have made our profession more humane for the young, the pregnant, and those who do not wish to (so wrongly) work double overtime all the days of their lives. And now we must view the other end of the age spectrum. Given continued competence, the issue then is one of the right to choose.

How do we establish competence in old age? There is a literature on social competence of the elderly. While the older adult may need more time to understand speech and find it more difficult to describe something to another individual, he or she is still adept at using his social and cognitive abilities to respond appropriately and to select higher quality relationships which are rewarding. Social competence is an important contributor to a strong sense of self, and social skill may be seen as a process rather than a stable personal trait. We need to make the respondents of our consideration, older people, partners in our research and deliberation.

Again you ask, "How do we establish professional competence in old age?" And I say "At any age?" Since we as a medical profession do not have a satisfactory measure of 'functional age' to replace age itself as a marker of suitability for employment, then perhaps our profession needs to address the issue of defining professional competence. Perhaps the Canadian Association of Gastroenterology could expand its prerogative and educational perspective to invite some of our 
very best senior persons to consider the definition of such guidelines. For these very same individuals for years have been assisting in defining the competence of our younger colleagues in examination and promotion processes. Perhaps performance does decline with age, but retirement rules must ensure the quality of service rendered rather than ensuring that physicians depart from their occupation. Let us hear from some of our senior gastroenterologists who have contributed so very, very much to our profession. Let us view the enlightened perspective which Queen's University has shown towards Ivan Beck as a model for other institutions. Let us admire the continued major contributions of Joe Sidorov and warmly acknowledge the nurturing attitude of Dalhousie University. Let us hope that the University of Alberta finds an appropriate way to continue to cherish the continued contributions of Dick Sherbaniuk. "There but for the grace of God go I." Will I have the pleasure and privilege of going 'their way' with grace and dignity?

\section{THE SIGN SAYS 'NO OLD PEOPLE HERE'}

Is our perspective of ageing in Canada to be a "demographic silhouette, a role incumbent or a silent mosaic of neglect and misinformation?" Why is there such a feeling of embarrassment, such a paucity of respect and prestige allotted to the elderly? Perhaps the status of the elderly in our society is directly related to the balance between the cost of supporting them and the social contributions they are perceived as making. Health profoundly affects life satisfaction, and although a high income does not necessarily assure a place among the most satisfied of individuals, low satisfaction almost always accompanies low income. While conventional wisdom in gerontology suggests that older married people are happier than older singles, we must reflect upon the special needs of "the invisible lives of Canada's gray gays." A lack of good friends is a tragedy for almost anyone, particularly for gay men. Let us cast no one aside.

While the proportion of older people remaining in the work force has steadily declined over the past 50 years in Canada and most other industrialized nations, it is hopeful that compulsory retirement will be abolished in Canada, and that while most people will nonetheless prefer to retire at or before age 65 , some will wish to exercise their right to continue employment. We have accepted the concept of 'work scheduling' at certain ages and education; training, job linkages and work sharing concepts must be explored.

Older workers will not take a significant number of jobs away from the currently unemployed; they will find jobs that are sitting empty because there are not enough skilled workers in the labor force to fill them.

Once we have affirmed that the older physician must be allowed to keep his or her place in the professional community, as much because important needs of such individuals will be defined in the future, we will likely find that, by chance, a senior physician may still elect for early retirement rather than continuing past work activity. What is important is that the individual has a choice in the retirement decision.

The workplace needs and will continue to need the experience and expertise of older workers; forced retirement of those who are still able to work may be a waste of talent which must be offset by an examination of incentives which will encourage the older worker to remain voluntarily in the work force.

Old people are sometimes categorized as senile, rigid in thought and manner, oldfashioned in morality, forgetful and boring. By thus stereotyping the elderly, the younger generation categorizes older people as different from themselves, and the elders may begin to enact the stereotyped ideas in a self-fulfilling prophecy. The elderly are not responsible for the inflation that has eroded their retirement savings; they are not responsible for retirement policies that were formulated to facilitate economic development in industrial nations; and early retirement "may be the result of a number of pressures related to a new mythology that workers over a certain age have no right to work."

Women are the major caregivers to the elderly as wives to elderly spouses and as middle-aged daughters to aged mothers. The term 'sandwich generation' describes the situation of middle-aged people, usually women, who find themselves torn between the competing obligations of responsibilities towards children, grandchildren, spouse and ageing parent. Widowhood is an expected life event and in 1980 in Canada there will be well over one million widowed persons. From our limited perspective, gentlemen, these will be our wives! Our daughters! From our own conscientious consideration of responsibility to provide our spouses support in the widowed years, we do provide for their physical needs, but what provision for their emotional needs?

Are their physical needs really going to be satisfied? After we are long gone, will the health care system treat our wives in a caring and conscientious manner? Will our wives have the private pension and consideration they so richly deserve? Will they enjoy their senior years in respect and dignity, or will they more likely live in a crowded, ill-funded nursing home, forced into community living by circumstances beyond their control? Take this dim but realistic perspective of the future and recognize your social responsibility, and your need to make important political changes in the care of the elderly before it is personally too late.

\section{REFERENCES}

1. Schlesinger B, Schlesinger R. Abuse of the Elderly: Issues and Annotated Bibliography. Toronto: University of Toronto Press, 1988.

2. Sodeman WA Jr, Saladin TA, Boyd WP Jr. Geriatric Gastroenterology, Philadelphia: WB Saunders Company, 1989

3. Marshall VW. Aging in Canada: Social Perspectives, 2 nd edn. Markham: Fitzhenry and Whiteside, 1987.

4. Kenney RA. Physiology of Aging - A Synopsis, 2nd edn. London: Year Book Medical Publishers Inc, 1989. 


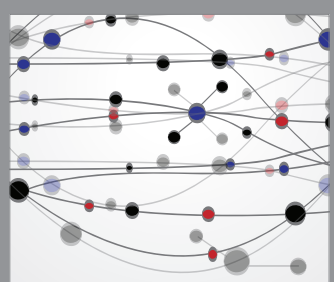

The Scientific World Journal
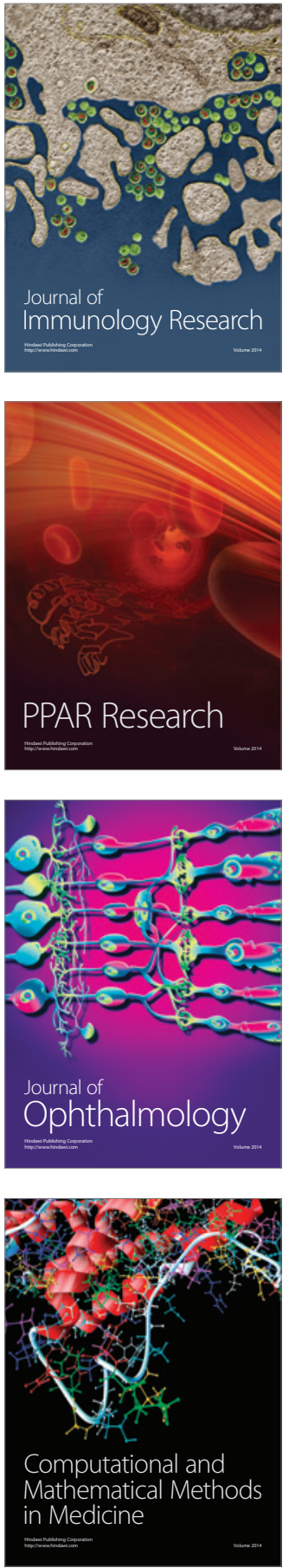

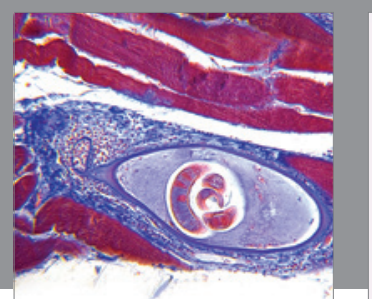

Gastroenterology Research and Practice

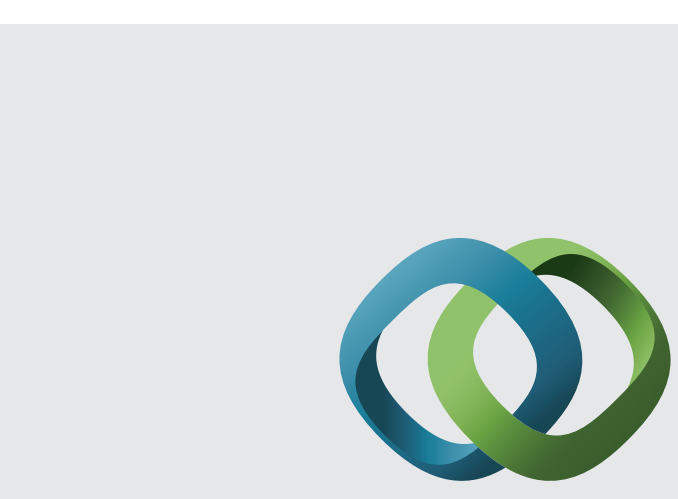

\section{Hindawi}

Submit your manuscripts at

http://www.hindawi.com
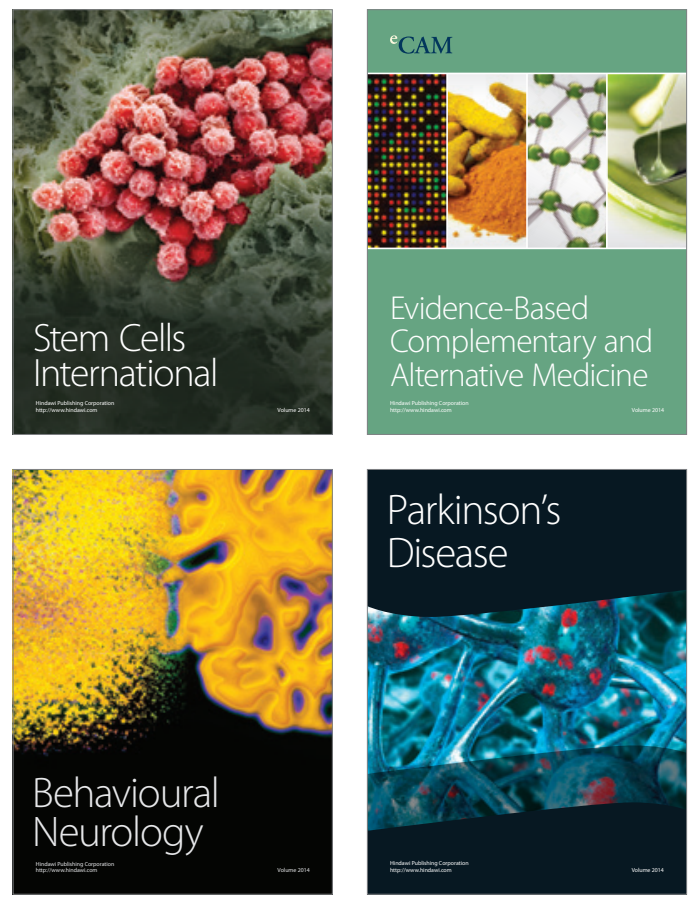
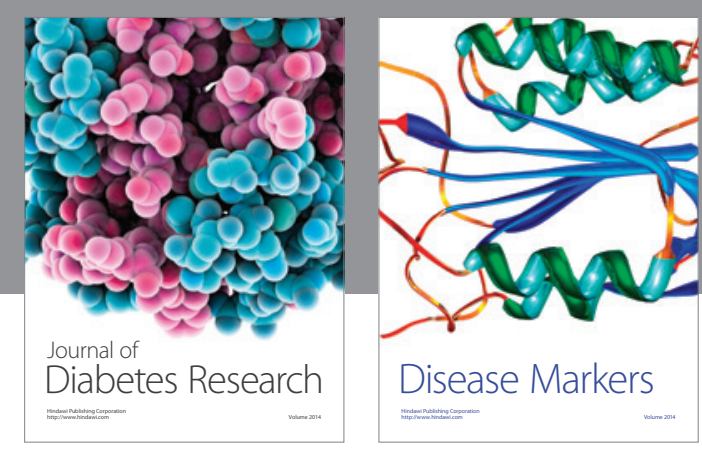

Disease Markers
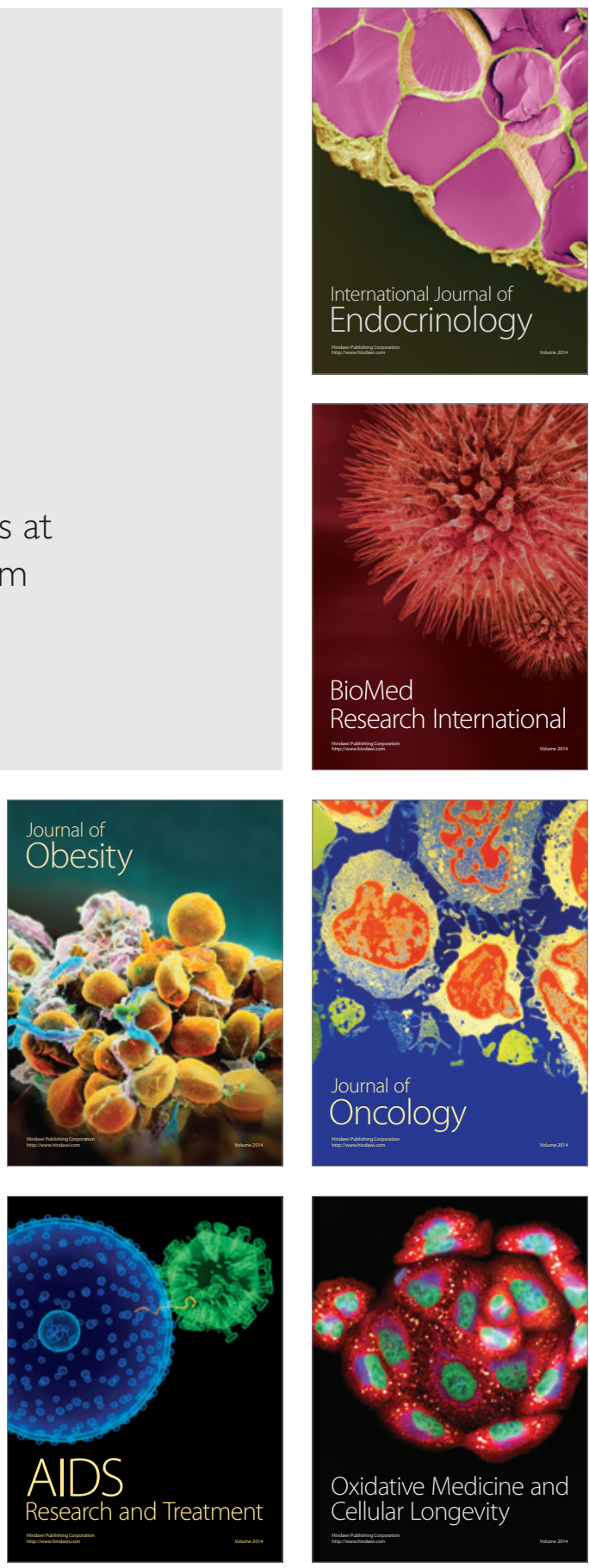